\title{
Griginal Is laparoscopic cholecystectomy effective \\ Apticle \\ in relieving dyspepsia in patients of cholelithiasis? A prospective study
}

\author{
Manas Aggarwal, Nitin Agarwal, Tushar S. Mishra, \\ Naveen Sharma, Seema Singh
}

\section{ABSTRACT}

Department of Surgery,

University College of Medical Sciences,

Delhi, India-110095.

Correspondence: Manas Aggarwal

Email:aggarwal.manas@gmail.com

Background: Laparoscopic cholecystectomy (LC) is routinely done for symptomatic gallstone disease; however, its role in relieving dyspeptic symptoms in cholelithiasis is controversial.

Aim: The study was designed to assess the role of laparoscopic cholecystectomy in relieving dyspeptic symptoms in patients having cholelithiasis with only dyspeptic symptoms.

Methods: Patients with cholelithiasis having only dyspeptic symptoms not attributable to other causes (like Helicobacter pylori) were subjected to laparoscopic cholecystectomy. Dyspepsia scores (Dyspepsia Severity Assessment Score-DSAS and Gastrointestinal Quality of Life IndexGIQLI) were measured before and after surgery and analyzed using Greenhouse-Geisser, McNemar's and ANOVA tests.

Results: 27 patients (M:F=1:26, mean age $=40.48 \pm 10.60$ years) having dyspepsia with asymptomatic gallstones were included in the study. There was significant improvement in DSAS $(20.11 \pm 4.36$ vs $28.63 \pm 3.42 ; \mathrm{p}<0.001)$ and GIQLI $(106.11 \pm 5.77$ vs $122.56 \pm 7.95 ; \mathrm{p}<0.001)$ after 2 months of LC. All symptoms improved individually; relief in early satiety and vomiting was the maximum (outcome benefit ratios $=0.954, p=0.007$ and 0.937 , $\mathrm{p}=0.005$ respectively). Multiple gallstones caused more dyspepsia than single $(\mathrm{p}=0.005)$. There was no significant difference between H. pylori positive and negative groups in terms of improvement of DSAS and GIQLI scores after LC ( $\mathrm{p}=0.897$ and $\mathrm{p}=0.375$ respectively; however dyspepsia was seen to improve significantly within both groups).

Conclusion: Dyspepsia may be a symptom of gallstone disease, and these patients can benefit from LC especially when early satiety and vomiting are the main symptoms. A larger sample size may offer more insight.

KEYWORDS: Dyspepsia; cholecystectomy; laparoscopic cholecystectomy; cholelithiasis. 


\section{Introduction}

Gallstone disease affects $10 \%$ to $20 \%$ of the western population, ${ }^{1}$ while the prevalence in India is $6.12 \% .^{2}$ There has been considerable debate regarding the symptomatology of cholelithiasis. Research done in 1948 gave the first impression of dyspepsia, especially flatulent dyspepsia, as being one of the manifestations of gallstone disease and advocated cholecystectomy for the same. ${ }^{3}$ Dyspepsia refers to a constellation of symptoms referable to the upper gastrointestinal tract, namely, epigastric discomfort or pain, postprandial heaviness; and early satiety. Associated complaints include: nausea, belching, bloating, and epigastric burn (heartburn). ${ }^{4}$

Many authors have studied the co-existence of dyspepsia and gallstones. Some studies, including a meta-analysis, have found this association inconsistent and have challenged the concept of gallstone dyspepsia. ${ }^{5}$ Another study found dyspeptic symptoms to be poorly relieved after cholecystectomy. ${ }^{6}$ In a prospective study, Mertens et al found that dyspeptic symptoms persisted even after a follow-up of 6 weeks after surgery. ${ }^{7}$ On the contrary, a prospective interventional study by Guiet al that analyzed the effect of laparoscopic cholecystectomy on dyspeptic symptoms showed promising results. ${ }^{8} \mathrm{~A}$ study published by Niranjan et al in 2000 has reported significant improvement in the majority of dyspeptic symptoms following cholecystectomy. ${ }^{9}$ These divergent studies raise more questions than answers; the coexistence of and possible causal association of gallstones and dyspepsia requires further scrutiny.

Laparoscopic cholecystectomy (LC) is currently not the advocated treatment for patients with dyspeptic symptoms and silent gall stones. However, in patients from geographical regions with a high prevalence of carcinoma gallbladder, e.g. Chile, North India (females) etc., where cholecystectomy in asymptomatic gallstone disease may be considered justifiable such kind of studies can be done. ${ }^{10}$ Thus, the purpose of this study was to determine the benefit of LC in patients of cholelithiasis with dyspepsia, with regards to symptom relief and change in quality of life.

\section{Materials and Methods}

Patients with symptoms of dyspepsia (epigastric pain, postprandial heaviness, early satiety, nausea, vomiting, heartburn, belching, and bloating) were selected from the surgical out-patient department of a tertiary teaching medical institution in North India for possible inclusion in the study, from November 2012 to January 2014. The research protocol was approved by the ethics committee of the institute. All of them were subjected to abdominal sonography to record the following features: presence and number of gallstones, status of gallbladder wall, presence of intra- and extra-hepatic biliary dilatation, presence of pericholecystic fluid, and, any other significant finding. An informed written consent was taken from the patients showing sonological evidence of gallstones. A few patients were excluded (including the patients that did not consent to be a part of the study,were not willing for surgery or endoscopy, wanted to get operated at other facilities or did not respond to our calls). The remaining patients were subjected to anupper gastrointestinal endoscopy (UGIE) and an antral biopsy. Patients with positive UGIE findings (hiatus hernia, severe esophagitis or gastritis) were excluded. Those who developed biliary colic were also subsequently excluded. The remaining patients formed our study group, which was classified into two subgroups on the basis of antral biopsy finding. (Flowchart 1a)

Patients who did not show evidence of H. pylori infection were classified as the 'Negative Group'. The severity of dyspepsia and the presenting symptoms were recorded and measured using two symptom scores, the Dyspepsia Severity Assessment Score (DSAS, Table 1) and the Gastrointestinal Quality of Life Index (GIQLI). ${ }^{11}$ These were then taken up for LC.

Those patients who showed evidence of $H$. pylori infection in the biopsy samples were classified as the 'Positive Group'. These were prescribed an anti H. pylori regimen (Cap. Lansoprazole $30 \mathrm{mg}$ BID, Tab. Tinidazole $500 \mathrm{mg}$ BID, and, Tab. Clarithromycin $50 \mathrm{mg}$ BID) orally for 14 days. This combination was selected due to relative affordability and availability. The symptom score of these patients were measured again after completion of the anti $H$. pylori regimen; those with complete resolution 
of symptoms were not offered cholecystectomy. Patients in whom the laparoscopic approach had to be abandoned due to difficult anatomy, intractable gallbladder adhesions with surrounding organs, or uncontrollable bleeding were excluded from the study,as these could have affected the postoperative symptom scores of the patients. Patients in whom surgery was completed by the conventional laparoscopic technique were analysed one month and two months after the surgery and, the DSAS and GIQLI scores were calculated again. (Flowchart 1b)

To study the relief after LC, comparison of the pre- and postoperative scores was done by applying Greenhouse-Geisser test. McNemar's test was used to study the relief in dyspeptic symptoms individually. Two factor repeated measures ANOVA test was used to see the role of parameters such as BMI, number of gallstones, fatty food intolerance etc., in affecting the change in dyspepsia scores.

\section{Results}

The flow of the study is depicted in Figures $1 \mathrm{a}$ and $1 \mathrm{~b}$. A total of 27 patients were eligible for final analysis (M:F=1:26). The mean age was $40.48 \pm 10.60$ years. Nine of the patients were obese (BMI $\geq 25)$. Fatty food intolerance was noted in $74.07 \%(20 / 27)$. The majority of patients were non-vegetarians $(55.56 \%, n=15 / 27)$. On abdominal sonography, $74.07 \%(20 / 27)$ were found to have multiple gallstones and $7.41 \%$ had an evidence of chronic cholecystitis (2 patients had a contracted gallbladder (GB) and 1 showed thickening of GB wall). Eleven $(40.74 \%)$ of them had been positive for H. pylori on gastric antral biopsy. Intraoperatively, a total of $55.56 \%(15 / 27)$ patients had dense adhesions between GB and omentum. Six patients $(22.22 \%)$ had an acutely edematous GB wall and two (7.41\%) had a fibrotic GB.

LC was seen to improve dyspepsia scores in all 27 patients. The mean DSAS and GIQLI scores significantly improved at one and two months after surgery (DSAS: $\mathrm{p}<0.001$, GIQLI: $\mathrm{p}<0.001$, Table 2). All eight symptoms studied individually improved after LC. Early satiety was the dyspeptic symptom with the highest outcome benefit ratio $(\mathrm{OBR}=0.954, \mathrm{p}=0.007)$, followed by vomiting,

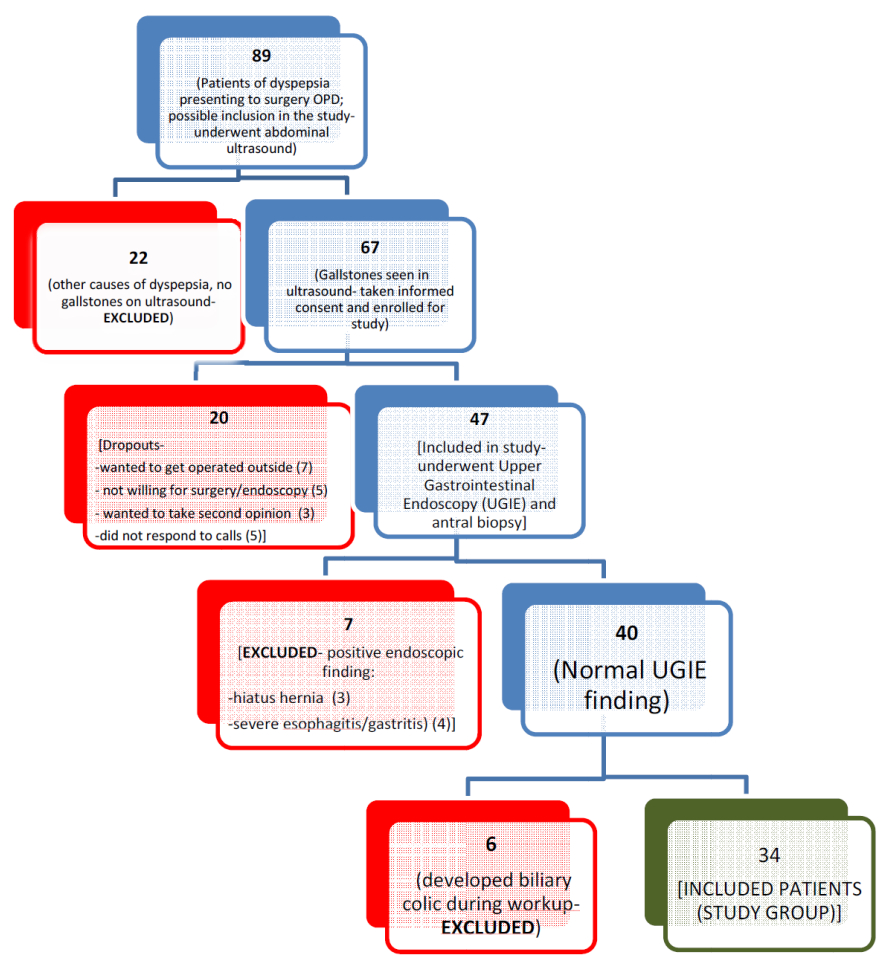

Flowchart 1a: Flow of study depicting number of patients from the initial phase to the final study group.

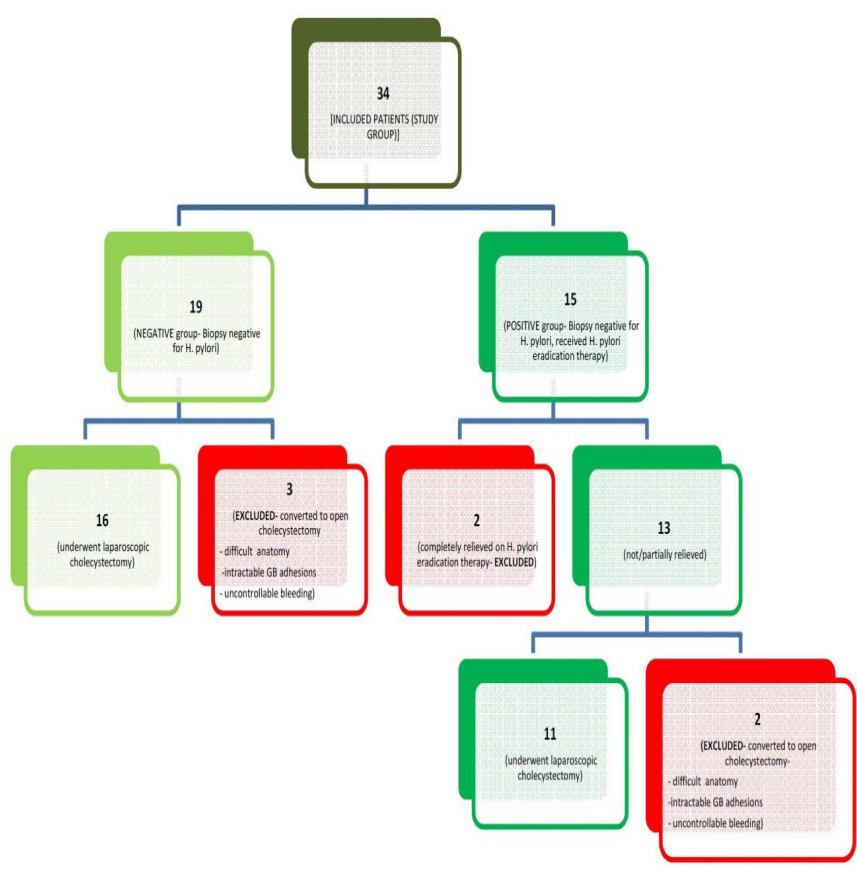

Flowchart 1b: Flow of study depicting further interventions in the study group. 
postprandial heaviness, bloating, belching, nausea and heartburn. Epigastic pain did not improve significantly $(\mathrm{OBR}=0.667, \mathrm{p}=0.077$, Table 3).

Other parameters assessed for confounding the improvement in GIQLI scores after LC revealed a significant relationship only in the case of single versus multiple gallstones (Table 4). A BMI of $\geq 25$, fatty food intolerance, non-vegetarian diet, contracted gallbladder, and dense adhesions did not affect improvement in GIQLI scores $(p<0.05)$. In the Positive Group, only $2 / 13$ patients $(15.38 \%)$ were completely relieved after 2 weeks of antiHelicobacter therapy.

Comparison between the Positive and Negative Groups in terms of improvement in DSAS and GIQLI scores after LC revealed no statistically significant difference $(\mathrm{p}=0.897$ for DSAS; $\mathrm{p}=0.375$ for GIQLI). However, both groups showed significant improvement in dyspepsia one month and two months after surgery (Table 5).

\section{Discussion}

Dyspepsia has been defined as a set of symptoms, related or unrelated to food ingestion, localized to the upper half of the abdomen. Dyspepsia has been divided into a) Organic dyspepsia, in which improvement of the underlying

\section{Table 1: Dyspepsia Severity Assessment Score (DSAS)}

\begin{tabular}{l|l}
\begin{tabular}{l|l} 
Component \\
Epigastric discomfort or pain
\end{tabular} & $\begin{array}{l}\text { Score } \\
\text { All of the time : } 0 \\
\text { Most of the time : } 1 \\
\text { Some of the time : } 2\end{array}$ \\
\cline { 1 - 1 } Postprandial heaviness & A little of the time : 3 \\
\cline { 1 - 1 } Early satiety & Never : 4 \\
\cline { 1 - 1 } Nausea & \\
\cline { 1 - 1 } Vomiting & \\
\cline { 1 - 1 } Heartburn & \\
\cline { 1 - 1 } Belching & \\
\cline { 1 - 1 } Bloating & \\
Minimum Score: zero (maximum dyspepsia), Maximum Score: 32 \\
(minimum dyspepsia)
\end{tabular}

Table 2: Change in scores (DSAS and GIQLI) after laparoscopic cholecystectomy in included patients of dyspepsia and gallstones $(n=27)$

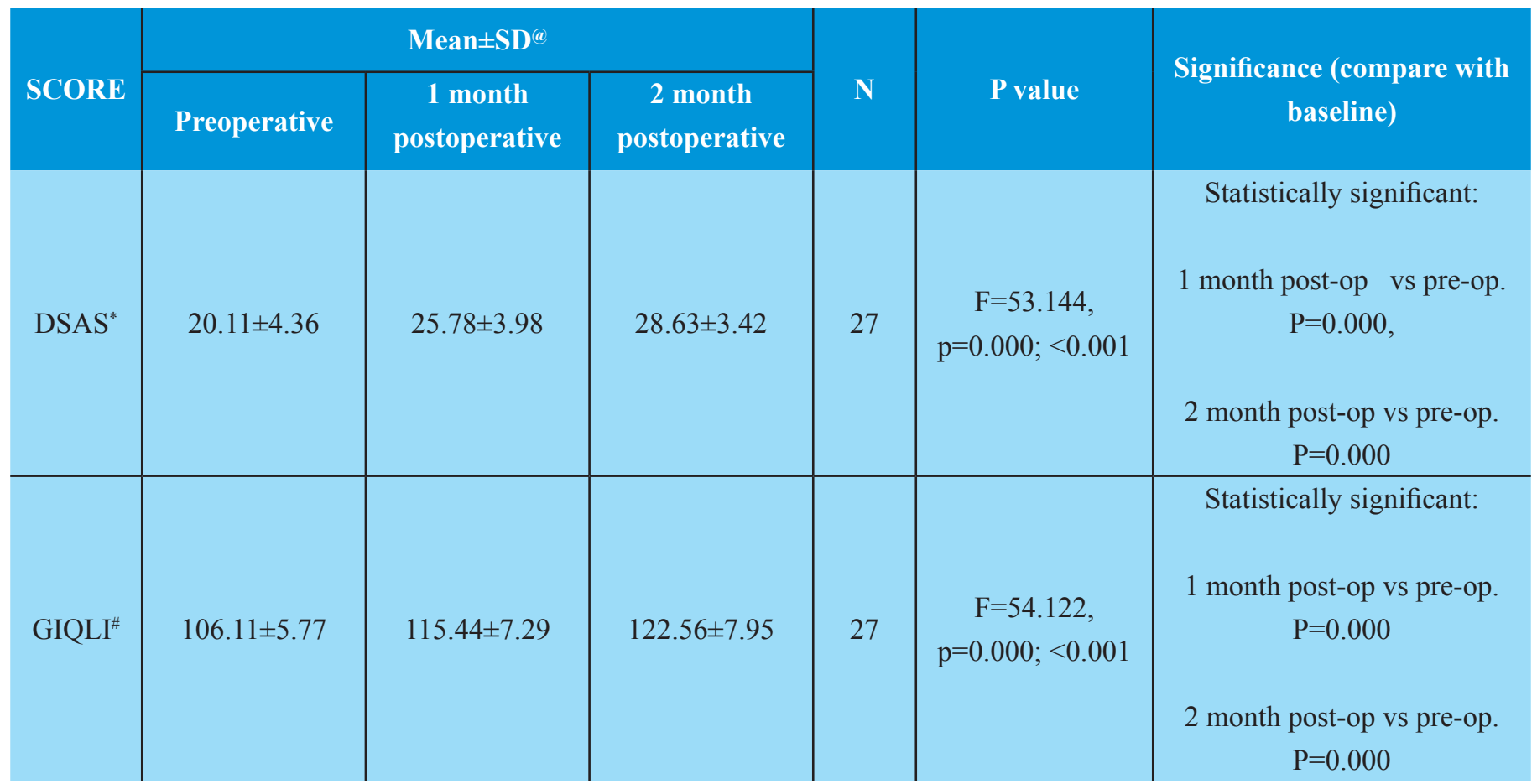

${ }^{\circledR} S D$ - Standard Deviation, "DSAS- Dyspepsia Severity Assessment Score, "GIQLI- Gastrointestinal Quality of Life Index,

Statistical Test applied-Greenhouse Geisser Test 
Table 3: Statistical analysis of the outcome of cholecystectomy on individual symptoms after 2 months of surgery

\begin{tabular}{|c|c|c|c|c|c|c|c|}
\hline \multirow{2}{*}{ Symptom } & \multicolumn{5}{|c|}{ Number of patients ( 2 month postoperatively) } & \multirow{2}{*}{$\begin{array}{l}\text { Mc Nemar's } \\
\text { test; p value }\end{array}$} & \multirow{2}{*}{$\begin{array}{l}\text { Statistical } \\
\text { Significance }\end{array}$} \\
\hline & Persistent & De novo & Improved & Deteriorated & Never suffered & & \\
\hline $\begin{array}{l}\text { Epigastric } \\
\text { Pain }\end{array}$ & 4 & 2 & 14 & 3 & 1 & 0.077 & $\mathrm{NS}^{*}$ \\
\hline $\begin{array}{l}\text { Postprandial } \\
\text { Heaviness }\end{array}$ & 2 & 1 & 21 & 2 & 2 & 0.029 & $S^{\#}$ \\
\hline Early Satiety & 1 & 0 & 21 & 0 & 5 & 0.007 & $S^{\#}$ \\
\hline Nausea & 3 & 0 & 16 & 1 & 7 & 0.006 & $S^{\#}$ \\
\hline Vomiting & 1 & 0 & 15 & 0 & 11 & 0.005 & $S^{\#}$ \\
\hline Heartburn & 2 & 1 & 12 & 1 & 12 & 0.019 & $S^{\#}$ \\
\hline Belching & 0 & 2 & 14 & 5 & 8 & 0.024 & $S^{\#}$ \\
\hline Bloating & 1 & 1 & 14 & 2 & 10 & 0.012 & $\boldsymbol{S}^{\#}$ \\
\hline
\end{tabular}

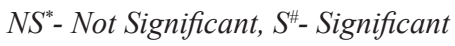

Table 4: Effect of number of gallstones in improvement in GIQLI scores in study group (n=27)

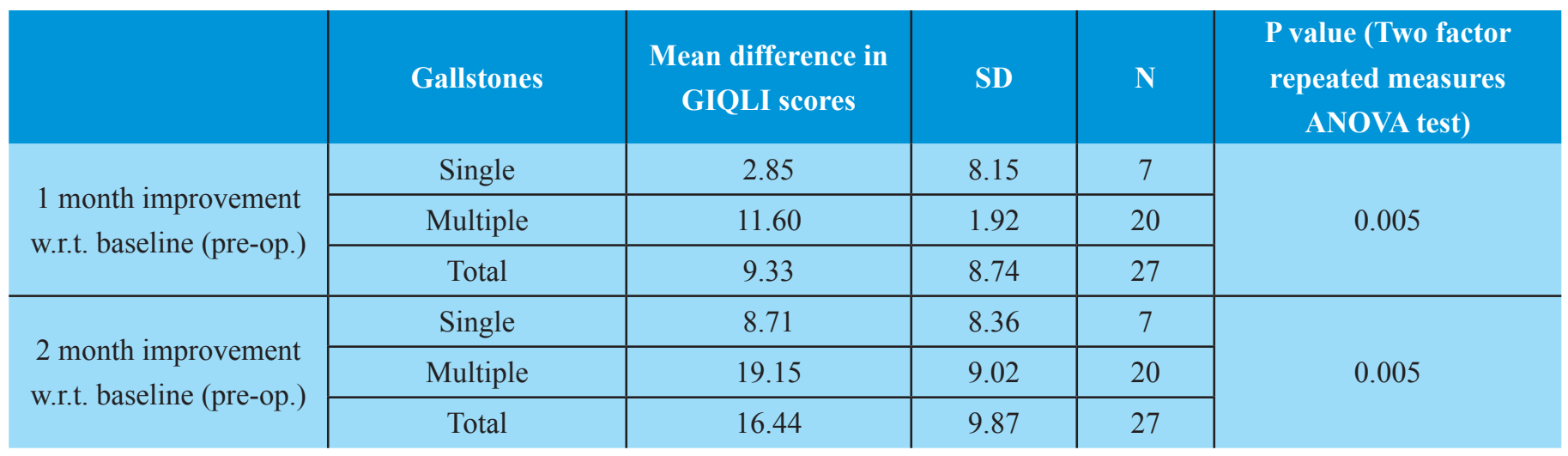

GIQLI- Gastrointestinal Quality of Life Index, N- number, SD-Standard Deviation.

condition would result in elimination of dyspepsia, e.g. peptic ulcer, biliopancreatic aetiologies, b) Functional dyspepsia, also known as nonorganic, idiopathic or essential dyspepsia, where no identifiable explanation for the symptoms could be said, and c) Non-investigated dyspepsia, which needs further investigations to deduce the cause. ${ }^{4}$ Peptic ulcer disease remains one of the most common causes of dyspepsia. There is level I evidence supporting the treatment of $H$. pylori infections in patients with duodenal or gastric ulcers. However, conflicting results are available regarding the benefits in nonulcer dyspepsia. $^{12,13}$
Gallstone disease is a common surgical problem worldwide; quite a number of patients of cholelithiasis present with only dyspeptic symptoms. According to Niranjan et al, laparoscopic cholecystectomy was responsible for relief of dyspeptic symptoms. Out of these, biliary pain, nausea, vomiting, and sour eructation had better outcome than belching, flatulence and heartburn. ${ }^{9}$ There has been conflicting evidence about the role of laparoscopic cholecystectomy in curing dyspepsia. ${ }^{14}$

This prospective observational study was designed to assess the relief in dyspeptic symptoms after laparoscopic cholecystectomy. Our study of 27 
Table 5: Comparison of dyspepsia scores in $\boldsymbol{H}$. pylori positive group and $\boldsymbol{H}$. pylori negative group after laparoscopic cholecystectomy

\begin{tabular}{|c|c|c|c|c|c|c|c|}
\hline \multirow[b]{2}{*}{ Score } & \multirow[b]{2}{*}{ Group } & \multicolumn{3}{|c|}{ Mean \pm SD } & \multirow[b]{2}{*}{ n } & \multirow[b]{2}{*}{ Pvalue } & \multirow[b]{2}{*}{ Significance } \\
\hline & & Preoperative & $\begin{array}{c}1 \text { month } \\
\text { postoperative }\end{array}$ & $\begin{array}{c}2 \text { month } \\
\text { postoperative }\end{array}$ & & & \\
\hline \multirow{2}{*}{ DSAS } & Positive group & $19.18 \pm 5.40$ & $25.27 \pm 3.85$ & $27.73 \pm 4.38$ & 11 & \multirow{2}{*}{$\begin{array}{c}\mathrm{F}=49.766, \\
\mathrm{p}=0.000 ;<0.001\end{array}$} & $\begin{array}{r}\text { Statistically } \\
\text { Significant } \\
\end{array}$ \\
\hline & Negative group & $20.75 \pm 3.51$ & $26.13 \pm 4.16$ & $29.25 \pm 2.54$ & 16 & & $\begin{array}{r}\text { Statistically } \\
\text { Significant } \\
\end{array}$ \\
\hline \multirow{2}{*}{ GIQLI } & Positive group & $107.82 \pm 4.94$ & $115.82 \pm 7.76$ & $121.64 \pm 8.98$ & 11 & \multirow{2}{*}{$\begin{array}{c}\mathrm{F}=49.59, \\
\mathrm{p}=0.000 ;<0.001\end{array}$} & $\begin{array}{r}\text { Statistically } \\
\text { Significant } \\
\end{array}$ \\
\hline & Negative group & $104.94 \pm 6.15$ & $115.19 \pm 7.19$ & $123.19 \pm 7.40$ & 16 & & $\begin{array}{l}\text { Statistically } \\
\text { Significant }\end{array}$ \\
\hline
\end{tabular}

@ SD- Standard Deviation, "DSAS- Dyspepsia Severity Assessment Score, " GIQLI- Gastrointestinal Quality of Life Index Statistical Test appliedGreenhouse Geisser Test

patients provides conclusive evidence in support of relief from various dyspeptic symptoms after laparoscopic cholecystectomy. Two dyspepsia severity scores were used to measure relief after surgery; one self-devised Dyspepsia Severity Assessment Score (DSAS) and another Gastrointestinal Quality of Life Index Score (GIQLI). Both the scores showed statistically significant increment in their respective mean values atone month and two months after surgery $(\mathrm{p}<0.001)$.

Mertens et al, after following up cholecystectomy patients for 6 weeks post-surgery, concluded that all symptoms show a reduction in their frequency after surgery, with the exception of diarrhoea. The reduction was noted in both biliary symptoms (upper abdominal pain, nausea, vomiting) and dyspeptic symptoms (heartburn, upper abdominal pain, flatulence). However, they observed persistence of dyspeptic symptoms in 10$40 \%$ of their patients, which could be ascribed to the shorter follow up in the study. ${ }^{7}$ The divergent results could also be due to the lack of an objective assessment by use of dyspepsia scores.

In our study, persistence of symptoms ranged from not at all for belching to a maximum of $16.66 \%$ for epigastric pain. However, usingscores for the grading of dyspepsia, a more objective improvement is brought out over the eight week long follow up.
Symptoms not considered typical for gallstone disease, like postprandial heaviness, early satiety, nausea, vomiting, belching, bloating and heartburn, which are otherwise considered classical dyspeptic symptoms, showed statistically significant improvement after laparoscopic cholecystectomy. The outcome benefit ratios in our study range from as high as 0.95 and 0.94 for early satiety and vomiting respectively to as low as 0.79 and 0.67 for heartburn and epigastric pain respectively, with ratios of other symptoms lying in between the extreme values. This proves that early satiety and vomiting are most likely to be due to gallstone diseaseand are thus most relieved after surgery. This result is also in accordance with a similar study published in 1998. They assessed symptomatic relief in 92 patients after cholecystectomy, and found vomiting and nausea to be highly relieved by surgery. ${ }^{8}$ A Scottish study including 97 patients reported cure rates of more than $80 \%$ for early satiety and nausea; however, bloating, constipation and use of psychotropic drugs were associated with a poor outcome after laparoscopic cholecystectomy. ${ }^{15}$ Thus, we conclude that LC can be offered when atypical symptoms exist, provided other causes have been ruled out.

Traditionally accepted causes of dyspepsia like high BMI, fatty or non-vegetarian diet, and specific changes of chronic cholecystitis were not seen to confound the 
results in our study, furthering the belief that gallstones were the cause of dyspepsia in these patients. The existence of features of previous cholecystitis indirectly proves that dyspepsia may at times be the only symptom of gallbladder disease. Patients with multiple gallstones can expect better relief of dyspepsia after laparoscopic cholecystectomy.

Only $15.38 \%$ of patients with normal endoscopic finding and antral biopsy positive for $H$. pylori achieved symptomatic relief by eradication therapy for $H$. pylori, whereas all the rest showed improvement after laparoscopic cholecystectomy. Thus, in these patients, gallstones may have been the predominant cause of dyspepsia. This is reinforced by the fact that this improvement was not statistically significantly different from $H$. pylori negative patients. Hence, H. pylori eradication is not expected to confound the results in our study group. Cases of dyspepsia $(n=22)$ without gallstones (expectedly H. pylori) were not included in the study. (Flowchart 1a)

\section{Conclusion}

Dyspepsia scores in all patients improved after laparoscopic cholecystectomy. It can therefore, be concluded that dyspepsia in these patients was a symptom of gallstone disease, and laparoscopic cholecystectomy alleviated dyspeptic symptoms in these patients.

Longer follow-up and more frequent measurements of dyspepsia symptom scores would provide further input on the relief offered by cholecystectomy in our patients. To apply our findings to the general population a study with a larger sample size should be performed. Validation of our self-devised DSAS score would add more credence to our findings.

\section{References}

1. Jackson PG, Evans SRT. Biliary system. In: Beauchamp RD, Evers BM, Mattox KL. Sabiston Textbook of Surgery: The Biological Basis of Modern Surgical Practice, 19th edition. Philadelphia, PA: Saunders Elsevier; 2008:14851501.

2. Unisa S, Jagannath P, Dhir V, Khandelwal C, Sarangi L, Roy TK. Population-based study to estimate prevalence and determine risk factors of gallbladder diseases in the rural Gangetic basin of North India. HPB (Oxford) 2011; 13:117-25.

3. Comfort MW, Gray HK, Wilson JM. The Silent Gallstone: A Ten to Twenty Year Follow-up Study of 112 Cases. Ann Surg. 1948;128(5):931-7.

4. Mearin F, Calleja JL. Defining functional dyspepsia. Rev EspEnferm Dig. 2011;103(12):640-7.

5. Kraag N, Thijs C, Knipschild P. Dyspepsia--how noisy are gallstones? A meta-analysis of epidemiologic studies of biliary pain, dyspeptic symptoms, and food intolerance. Scand J Gastroenterol. 1995;30(5):411-21.

6. Diehl AK. Symptoms of gallstone disease. Baillieres Clin Gastroenterol. 1992;6(4):635-57.

7. Mertens MC, De Vries J, Scholtes VP, Jansen P, Roukema JA. Prospective 6 weeks follow-up post-cholecystectomy: the predictive value of pre-operative symptoms. $J$ Gastrointest Surg. 2009;13(2):304-11.

8. Gui GP, Cheruvu CV, West N, Sivaniah K, Fiennes AG. Is cholecystectomy effective treatment for symptomatic gallstones? Clinical outcome after long-term follow-up. Ann R CollSurg Engl. 1998;80(1):25-32.

9. Niranjan B, Chumber S, Kriplani AK. Symptomatic outcome after laparoscopic cholecystectomy. Trop Gastroenterol. 2000;21(3):144-8.

10. DeVita VT Jr, Lawrence TS, Rosenberg SA (ed.) Cancer: Principles \& Practice of Oncology, 8th edition, volume 1. Philadelphia, PA: Lippincott Williams and Wilkins; 2008: 1176-7.

11. Eypasch E, Williams JI, Wood-Dauphinee S, Ure BM, Schmülling C, Neugebauer E et al. Gastrointestinal Quality of Life Index: development, validation and application of a new instrument. Br J Surg. 1995;82(2):216-22.

12. Howden CW. For what conditions is there evidence-based justification for treatment of Helicobacter pylori infection? Gastroenterology. 1997;113:107-12.

13. Blum AL, Talley NJ, O'Moráin C, van Zanten SV, Labenz J, Stolte M, et al. Lack of effect of treating Helicobacter pylori infection in patients with nonulcer dyspepsia. Omeprazole plus Clarithromycin and Amoxicillin Effect One Year after Treatment (OCAY) Study Group. $N$ Engl $J$ Med. 1998;339(26):1875-81.

14. Egbert AM. Gallstone symptoms. Myth and reality. Postgrad Med. 1991;90(5):119-26.

15. Luman W, Adams WH, Nixon SN, Mcintyre IM, HamerHodges D, Wilson $\mathrm{G}$ et al. Incidence of persistent symptoms after laparoscopic cholecystectomy: a prospective study. Gut. 1996;39(6):863-6. 